required in these contexts can be deemed much more practical and comprehensive than in other reported scenarios.

\section{References}

KANTER, J. (1989) Clinical case management: definition, principles, components. Hospital \& Community Psychiatry, 40, 361.
Lomas, G. (1979) Long-Term Mental Illness in Hackney. Centre for Environmental Studies Working Note 565.

Ruch, M. et al (1989) Coordinating care for people disabled by long-term mental illness living in the community. Psychiatric Bulletin, 13, 290-291.

WITHRIDGE, T.F.(1989) The assertive community treatment worker: an emerging role and its implications for professional training. Hospital and Community Psychiatry, $40,620$.

\title{
Lunacy, insanity, and the purpose of psychiatry
}

\author{
Bruce G. Charlton, Anatomy Department, University of Glasgow, Glasgow G12 8QQ
}

Insane: Not of sound mind, mad, mentally deranged. Oxford English Dictionary.

Lunatic: Originally, affected with the kind of insanity that was supposed to have recurring periods dependent on the changes of the moon. Oxford English Dictionary.

Madness need not be regarded as an illness. Why shouldn't it be seen as a sudden-more or less sudden-change of character. Wittgenstein, 1980.

Within psychiatry there are two distinct tendencies. On the one hand there is the tendency for the subject to expand beyond its concern with psychological medicine and encroach upon diverse aspects of society. "The psychiatrist who believes that the phenomena of mental illness can be explained on the basis of a universal theory ... finds little difficulty in inflating his theory to explain not only mental disease but also normal human behaviour, interpersonal relations, and ultimately human affairs" (Miller, 1970).

On the other hand there is a countervailing movement which seeks to limit psychiatry, and to contain it within boundaries. Psychiatry should be restricted for reasons which are both moral and practical. The practice of "triage", or discrimination in treatment, is desirable as well as efficient.

Ethical objections relate to the dangerous effects of concepts derived from the study of morbid psychology - "the caricatures of normal human behaviour that present as psychoses or neuroses" (Miller, 1970) - when they are applied beyond what is strictly justified on either therapeutic or forensic grounds. There is not space here to rehearse the arguments against what might be called the "psychiatrisation" of society, except that it is likely to be even worse than the currently excessive state of medicalisation (Woods, 1984).

But the pragmatic case alone seems decisive. Psychiatry is clearly more effective in some of its interventions than others. Common sense would imply that emphasis should be placed on effective actions rather than indefinable or marginal benefits. Therefore, we already have some guidelines towards defining the purpose of the subject.

So far this is relatively uncontroversial: most people would agree with at least the idea of limits and the notion of doing what one is good at. The difficulties begin when we try to decide how limits should be established and upon what principles they should be based. Because cases are frequently unclear, the boundary at which intervention should be attempted is blurred, and the conflict between opposing moral principles may become acute.

The reason would seem to lie in the fact that psychiatry has historically developed with two distinct purposes which, although they overlap, may at times contradict each other. I have chosen the names Lunacy and Insanity for the objects of these purposes, because the terms capture something of the contrast within the subject - but I could equally well have chosen Therapeutics and Forensics which puts the matter in a similar perspective.

Psychiatry can regard the behaviour of a given person in two contexts: that of the subject's own 
past, or that of society as a whole. In other words, longitudinal or cross-sectional.

The longitudinal view is related to the term "lunatic" because it focuses upon "recurring periods" of insanity. People who have been normal become insane: that is, they become abnormal in the context of their previous lives: "a sudden - more or less sudden, change of character." Intervention is justified (or not) in terms of returning individuals to their previous state: their previous "character". And on pragmatic grounds it has been well established that psychiatric illness of the acute kind, which happens with a background of a stable and "adequate" personality, has the best response to therapeutic interventionwhether the nature of that illness is affective, schizophrenic or neurotic. Again, intervention is justified both morally and pragmatically.

I have introduced a term here - "adequate" or "normal" personality - which overlaps with the other perspective under consideration. This leads onto a consideration of the other main reason to justify psychiatric intervention-when a person's cross-sectional mental state is abnormal. The kind in insanity defined by "not of sound mind, mad, mentally deranged". In this situation it does not matter much whether or not subjects habitually behave in a mad fashion - the point is that they are mad now, and something has to be done about it. I have perhaps caricatured this idea by using the term "forensic", but the essential point is that our interventions in this case are not dictated primarily by concern for the welfare of the patient. An intervention has the aim of containing the abnormal behaviour, whether or not there is any prospect for long-term change. For example, a violent madman must be restrained or a suicide must be prevented - even if, as is frequently the case, to do so will have negative implications for the subject in the longer term (reinforcing attentionseeking behaviour, encouraging the sick role, diminishing the sense of personal responsibility, or whatever).

I do not wish to imply that this forensic intervention to restrain abnormal behaviour is wrong: quite the contrary. This is something which all societies must do, whether they like it or not. For example, no known society in history has solved the problem of dealing with so-called psychopaths. We are still faced with the options of tolerating them or eliminating them (e.g. prison, exile or death), and nothing seems to do significant good in a therapeutic sense. Similar considerations apply to the long-term chronically abnormal - the personality disordered, mentally deficient and even the chronically psychotic. In such cases effective psychiatric intervention is restricted to correcting deviations from a stable condition of abnormality-most effort is directed towards establishing an appropriate environmental milieu.
I wish to suggest that the main business of modern psychiatry lies in the treatment of "lunatics" rather than "insanity". The principal aim of psychiatric intervention should be to restore mentally ill people to their previous state. This has implications for the way the subject is regarded, and perhaps provides some pointers for future development.

While recognising that we cannot escape from some notion (however broad) of what constitutes normal behaviour, the therapeutic purpose is focused upon a longitudinal perspective. Therefore, in assessing a patient, the psychiatrist is looking for evidence of discontinuity or qualitative change of a dysfunctional kind. This has not, perhaps, been sufficiently recognised. We need to develop "objective" correlates of such changes, analogous to life events, which can be used to predict the probability of treatable psychiatric illness. For example, what are the best questions to ask, who are the witnesses likely to have the most useful information, and which subjective symptomatic changes are most reliably reported?

The recent emphasis on tightening-up diagnostic criteria based on the mental state examination seem to have gone as far as is useful, and there is a backlash towards the idea of a continuum of psychosis (Lancet, 1985; Crow, 1986). Exact cross-sectional determinations of the boundaries of normal behaviour and emotion are mainly a forensic, rather than therapeutic, technique; and pay insufficient attention to what is normal within a subject's own life. Grossly abnormal behaviour will always have implications for forensic intervention, but we should be careful not to confuse this with the case for therapeutic intervention. Although the boundary will sometimes be blurred, it should not be forgotten that psychiatrists may become involved with lunatics and the insane for quite different reasons.

Psychiatry grew up as a mainly forensic subject where the interests of medicine overlapped with law. The continued (and increasing) importance of the Mental Health Act bears witness to this state. The persistent controversy over how to regard psychopathy is evidence that this overlap is a genuinely grey area. But the possibility of effective therapeutic intervention has developed much more recently, and without being explicitly distinguished from what went before. It would be useful if we started to be explicit about this difference, and concentrated our efforts on the treatment of "lunacy" where we have both the strongest moral justification and the greatest chance of success.

\section{References}

Crow, T. J. (1986) The continuum of psychosis and its implication for the structure of the gene. British Journal of Psychiatry, 149, 419-429. 
Lancet (Editorial) (1985) Irritability in psychiatric nosologists. Lancet, $i i, 1223$.

Miller, H. (1970) Psychiatry: medicine or magic. British Journal of Hospital Medicine, 3, 122-126.

WitTGENSTEIN, L. (1980) Culture and Value. (Translated by Peter Winch.) Oxford: Basil Blackwell: Dated 1946,p. 54e. Woods, G. (1984) The Myth of Neurosis. London: Macmillan.

\section{Careers in psychiatric specialities}

\section{Rehabilitation psychiatry}
Dawn Black, Consultant Psychiatrist, Hope Hospital, Eccles New Road, Salford 6, Lancashire; ElSPETH GUTHRIE, Senior Registrar in Psychiatry; Gaskell House, Swinton Grove, Manchester M13 0EW; and KeITH BRIDGES, Consultant Psychiatrist with Special Responsibility for Rehabilitation, Manchester Royal Infirmary, Oxford Road, Manchester M13 9BX

The career paths of many trainees in psychiatry are influenced by their experience of a six month SHO/ registrar training post in a particular speciality. Not all trainees, however, may be aware of the training requirements for a specialist consultant post, career prospects and most importantly of the practicalities of working on a day to day basis as a specialist consultant or a consultant with special interest or responsibility. Furthermore, some SR trainees may have a limited choice of placement in a SR training scheme and with the diminishing availability of pure general psychiatry consultant posts, a year's training at senior registrar level may determine a trainee's whole career.

This paper will be the first of a series of eight which will aim to provide some insight into the following specialities of adult psychiatry and to delineate the training requirements for and the practical aspects of undertaking such posts. Topics to be covered are rehabilitation psychiatry, mental handicap, old age psychiatry, psychotherapy, forensic psychiatry, community psychiatry, liaison psychiatry and addictions.

Further information will be available in the updated JCHPT handbook to be published later this year.

\section{Psychiatric rehabilitation}

\section{Definition}

Rehabilitation is a process which aims to enable a person to achieve and maintain his/her best level of psychosocial functioning, adjustment, resourcefulness and satisfaction with different aspects of his/her life and care, even when he/she has an unremitting illness and impaired insight. For the majority of patients with chronic disabilities this form of care may be needed either continuously or intermittently throughout a long illness career. Its principles apply to patients in different settings throughout a health district, and depend on close links between services in different locations. A comprehensive service consists of a range of facilities, a stable workforce of skilled staff of different disciplines and backgrounds, a variety of interventions, a long-term commitment to patients and services, and usually collaborative work involving statutory and non-statutory organisations and personnel. Its success depends on adequte funds, and effective mechanisms for case management and for ensuring that limited resources are being deployed appropriately. 